\title{
An open-label study examining the effect of pharmacological treatment on mannitol- and exercise-induced airway hyperresponsiveness in asthmatic children and adolescents with exercise-induced bronchoconstriction
}

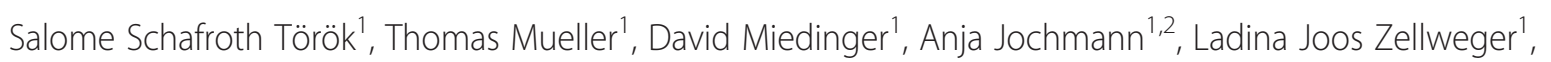
Sabine Sauter ${ }^{3}$, Alexandra Goll ${ }^{3}$, Prashant N Chhajed ${ }^{1}$, Anne B Taegtmeyer ${ }^{4}$, Bruno Knöpfli ${ }^{3}$ and Jörg D Leuppi ${ }^{5,6^{*}}$

\begin{abstract}
Background: Mannitol- and exercise bronchial provocation tests are both used to diagnose exercise-induced bronchoconstriction. The study aim was to compare the short-term treatment response to budesonide and montelukast on airway hyperresponsiveness to mannitol challenge test and to exercise challenge test in children and adolescents with exercise-induced bronchoconstriction.

Methods: Patients were recruited from a paediatric asthma rehabilitation clinic located in the Swiss Alps. Individuals with exercise-induced bronchoconstriction and a positive result in the exercise challenge test underwent mannitol challenge test on day 0 . All subjects then received a treatment with $400 \mu \mathrm{g}$ budesonide and bronchodilators as needed for 7 days, after which exercise- and mannitol-challenge tests were repeated (day 7). Montelukast was then added to the previous treatment and both tests were repeated again after 7 days (day 14).

Results: Of 26 children and adolescents with exercise-induced bronchoconstriction, 14 had a positive exercise challenge test at baseline and were included in the intervention study. Seven of 14 (50\%) also had a positive mannitol challenge test. There was a strong correlation between airway responsiveness to exercise and to mannitol at baseline $(r=0.560, p=0.037)$. Treatment with budesonide and montelukast decreased airway hyperresponsiveness to exercise challenge test and to a lesser degree to mannitol challenge test. The fall in forced expiratory volume in one second during exercise challenge test was $21.7 \%$ on day 0 compared to $6.7 \%$ on day $14(p=0.001)$ and the mannitol challenge test dose response ratio was $0.036 \% / \mathrm{mg}$ on day 0 compared to $0.013 \% / \mathrm{mg}$ on day 14 ( $p=0.067$ ).
\end{abstract}

Conclusion: Short-term treatment with an inhaled corticosteroid and an additional leukotriene receptor antagonist in children and adolescents with exercise-induced bronchoconstriction decreases airway hyperresponsiveness to exercise and to mannitol.

Keywords: Exercise-induced bronchoconstriction, Airway hyperresponsiveness, Children, Exercise challenge test, Mannitol challenge test

\footnotetext{
* Correspondence: joerg.leuppi@ksli.ch

${ }^{5}$ Internal Medicine, Kantonal Hospital Baselland and University of Basel, Basel,

Switzerland

${ }^{6}$ University Clinic of Internal Medicine, Kantonsspital Baselland, Liestal,

Switzerland

Full list of author information is available at the end of the article
} 


\section{Background}

Airway hyperresponsiveness (AHR), a characteristic feature of asthma, is an abnormal increase in airflow limitation that follows exposure to a stimulus that would be innocuous in a healthy person [1]. There are two main types of bronchial provocation test (BPT): direct and indirect tests. The direct airway challenges using methacholine and histamine, have a direct effect on smooth muscle cells that causes contraction and leads to a narrowing of the airways [2]. The indirect tests can be subdivided into physical stimuli such as exercise, eucapnic voluntary hyperventilation, cold air hyperventilation, hypertonic saline and mannitol, and the pharmacological agent adenosine monophosphate. These indirect BPTs cause airflow limitation through inducing a release of mediators from inflammatory cells and sensory nerves. The mediators act on smooth muscle cell causing contraction which results in airway narrowing [2-4].

The exercise challenge test (ECT), an indirect BPT is used to diagnose and assess exercise-induced bronchoconstriction (EIB), which is a common manifestation of asthma, especially in childhood [5,6]. EIB is defined as a transient increase in airway resistance that occurs after vigorous exercise and is seen in $70 \%$ to $90 \%$ of individuals with asthma and in approximately $11 \%$ of the general population with no known asthma $[7,8]$.

An indirect bronchial provocation test using dry powder inhalation of mannitol has been developed by Sandra Anderson in Australia [9]. In comparison to many other BPT it is cheaper, portable and faster to perform [2]. This new BPT leads to an increase in the osmolarity of the airway surface leading to the release of mediators from a variety of inflammatory cells [2]. In vitro, mannitol causes a rapid release of histamine from human lung mast cells, with the maximum release occurring at two to three times physiological osmolarity. Asthmatic subjects with airways responsiveness to exercise and hypertonic saline have also been shown to react to inhaled mannitol $[10,11]$.

Both adults and children with current asthma can be accurately identified using the mannitol challenge test (MCT) [9,12]. In children, Subbarao has suggested the MCT as a safe, faster and repeatable alternative to a challenge test with methacholine [12]. In clinical practice, mannitol challenge has been proven to be both a sensitive and valid test for demonstrating the effects of inhaled corticosteroids (ICS) in asthma and to predict future asthma exacerbations [13,14]. Whether MCT and/or ECT can detect a treatment response to ICS and montelukast in children and adolescents with EIB is not known.

The aim of the current study was therefore to compare treatment response to budesonide and additional montelukast as assessed by airway hyperresponsiveness to exercise and to mannitol challenge tests in children and adolescents with exercise-induced bronchoconstriction.

\section{Methods \\ Study design}

Twenty six children and adolescents with physician diagnosed asthma were recruited from the Alpine Children's Hospital Davos (Switzerland). The study was carried out according to the 1975 Declaration of Helsinki (modified in 1983) and in adherence to local guidelines for good clinical practice. The protocol was approved by the local ethics review committee (Kanton Graubünden Switzerland, reference number 21/07), and written informed consent was obtained from all subjects' parents or guardians.

During their stay in the hospital, all individuals underwent a structured multimodal rehabilitation program.They received an individually adapted physical activity program with the aim of supporting fitness and motivating them to include physical activity as part of their daily routine, and encouraging them to maintain an active lifestyle on a long-term basis. The daily exercise program focused on endurance activities to improve aerobic performance. Physical coordination and flexibility skills were also developed. A typical exercise session lasted 60 to 90 minutes, was performed in groups and was supervised by exercise therapists: for example in summertime $4 \mathrm{~km}$ walks or ball games, in wintertime indoor swimming plus water games, ice sports or snowboarding and an activity once per week that involved 4-5 hours of either hiking (in summertime) or 4-5 hours of downhill skiing (in wintertime). Other activities included ergometric cycling.

Spirometry was measured at baseline and all patients underwent ECT and MCT on two different days (day 0). Children found to have a positive ECT were then subsequently included in the therapeutic monitoring part of the study. Children received standard-treatment with $400 \mu \mathrm{g}$ budesonide per day and inhaled bronchodilators as needed for 7 days, after which ECT and MCT were repeated (day 7). Montelukast was added to the previous treatment at the beginning of the second week and ECT and MCT were repeated again after 7 days (day 14).

\section{Subjects}

Study inclusion criteria were children or adolescents with physician diagnosed asthma. We excluded patients if they had a pulmonary disease other than asthma, an upper respiratory tract infection in the last 3 weeks or an emergency department visit for treatment of asthma within 1 month prior to the baseline visit. Patients were also excluded from the study if they received methylxanthines, cromoglycate, anticholinergics or antihistamines within 
2 weeks or systemic corticosteroids within 1 month before the first visit.

\section{Spirometry}

Spirometry was performed using American Thoracic Society criteria [15]. A spirometer (EasyOne ${ }^{\mathrm{TM}}$, ndd, Zurich, Switzerland) was used to measure forced vital capacity (FVC) and one second forced expiratory volume (FEV1). Spirometry was performed until two repeatable values of FEV1 within $100 \mathrm{ml}$ were obtained. The higher of the two repeatable FEV1 values was recorded and the percentage of predicted values was calculated [16].

\section{Exercise challenge test}

ECT was performed according to the ATS guidelines for exercise challenge testing [17]. Briefly, ECT was performed using a treadmill with adjustable speed and grade. Heart rate was monitored using a pulse oximeter. Treadmill speed and grade were chosen to produce 4-6 minutes of exercise at near-maximum targets with a total duration of exercise of 8 minutes. Spirometry was performed before exercise and then serially at 2, 5, 10 and 15 min after cessation of exercise. Response to ECT was positive when a fall in $\mathrm{FEV}_{1}$ of $\geq 15 \%$ after challenge was reached.

\section{Mannitol challenge test}

MCT test was performed according to the protocol by Anderson et al. which is further summarized elsewhere [9]. Briefly, doses consisting of 0 (empty capsule acting as a placebo), 5, 10, 20, 40, 80, 160, 160 and $160 \mathrm{mg}$ of mannitol were administered via an inhaler device (Pharmaxis Ltd., Frenchs Forrest, NSW, Australia). The 80 and $160 \mathrm{mg}$ doses were given in multiples of $40 \mathrm{mg}$ capsules. After the inhalation of each dose the patient was told to hold their breath for five seconds. Two FEV 1 maneuvers were performed 60 seconds after each dose and the highest $\mathrm{FEV}_{1}$ measurement was recorded. The $\mathrm{FEV}_{1}$ value measured after the $0 \mathrm{mg}$ capsule was taken as the pre-challenge $\mathrm{FEV}_{1}$ and was used to calculate the percentage decrease in $\mathrm{FEV}_{1}$ in response to MCT. The challenge was stopped when a $15 \%$ fall in $\mathrm{FEV}_{1}$ was documented or a cumulative dose of $635 \mathrm{mg}$ had been administered. Response-dose-ratio, which is an index of activity $\left(\mathrm{RDR}=\%\right.$ of maximum fall in $\mathrm{FEV}_{1} /$ maximum dose mannitol given), was calculated for all subjects. The provoking dose of mannitol to cause a $15 \%$ fall in $\mathrm{FEV}_{1}$ $\left(\mathrm{PD}_{15}\right)$ was calculated by linear interpolation of the relationship between the percent fall in $\mathrm{FEV}_{1}$ at the end of the MCT test and the cumulative dose of mannitol required (in $\mathrm{mg}$ ) to provoke this fall. Response to $\mathrm{MCT}$ was considered positive when a fall in $\mathrm{FEV}_{1}$ of $\geq 15 \%$ occurred after a cumulative mannitol dose of $635 \mathrm{mg}$ or less.

\section{Statistical analysis}

Continuous variables are expressed as mean \pm standard deviation (SD) or as medians with interquartile range (IQR), and categorical variables were expressed as relative frequencies and percentages. Continuous variables were compared by using non-parametric tests. For all data analyses, we used the statistical software package SPSS V.19 (SPSS Inc., Chicago, USA). A p-value of $<0.05$ was considered statistically significant. We calculated the efficiency of the MCT to diagnose a significant drop in FEV1 during exercise as follows: (true-positive results [MCT and ECT positive] + true-negative results [MCT and ECT negative])/number of subjects investigated.

\section{Results and discussion}

\section{Baseline characteristics and correlation of MCT with ECT}

Twenty-six children and adolescents (age 13.5 \pm 2.7 years; 21 males) were included in the study. Of these 14 had a positive response to the ECT and therefore proceeded to the treatment part of the study. These 14 subjects ( $2 \mathrm{fe}$ males and 12 males) were aged 9 to 20 years $(14.1 \pm$ 3.1 years) and had a mean body mass index (BMI) of $27.8 \pm 8.8 \mathrm{~kg} / \mathrm{m}^{2}$. Asthma had been known for a mean of 5.4 years (range 0 to 15 years). Three individuals were current smokers.

Lung function at baseline was normal in all patients with a mean FEV1 of $111 \%$ predicted $( \pm 16 \%)$ and a mean FVC\% of $115 \%$ predicted $( \pm 17 \%)$. Fourteen patients had a positive ECT and therefore proceeded to optimized treatment, their baseline characteristics and lung function are shown in detail in Table 1 where the results are stratified according to the MCT outcome. Of these 14 ECT positive patients, 7 also had a positive MCT (Table 2). There was high correlation between maximum fall in FEV1 during exercise test and RDR $(r=-0.560$, $\mathrm{p}=0.037)$. Median drop in FEV1 during exercise in patients with a positive MCT was higher than those with a negative MCT but the difference was not statistically significant $(p=0.286)$. As expected those with positive MCT had a higher RDR to mannitol ( $p=0.029)$.

\section{Effect of treatment regimen on BHR to exercise and mannitol}

After seven days of inhaling $400 \mu \mathrm{g}$ budesonide per day, 10 out of 14 subjects had become unresponsive to ECT, while 1 out of 7 subjects had become unresponsive to $\mathrm{MCT}$ and one individual became positive in the MCT (Table 2).

After adding montelukast to the treatment regimen of those four who had a positive ECT at day 7 three had become unresponsive to ECT whereas one individual had become responsive to ECT again. Five out of the seven individuals who were responsive to MCT became unresponsive, however the remaining two responsive 
Table 1 Baseline characteristics of the 14 participants with exercise induced bronchoconstriction

\begin{tabular}{|c|c|c|c|c|c|c|c|c|c|}
\hline Subject & BMI $\left(\mathrm{kg} / \mathrm{m}^{2}\right)$ & Age & FEV1 (L) & $\begin{array}{l}\mathrm{FEV} 1 \% \\
\text { predicted }\end{array}$ & $\begin{array}{l}\text { FVC } \\
\text { (liter) } \\
\end{array}$ & $\begin{array}{l}\text { FEV1\% } \\
\text { predicted }\end{array}$ & $\begin{array}{l}\text { Max fall FEV1 } \\
\text { in ECT (\%) }\end{array}$ & $\begin{array}{l}\text { RDR mannitol } \\
(\% / \mathrm{mg})\end{array}$ & $\begin{array}{l}\text { PD15 } \\
\text { mannitol }\end{array}$ \\
\hline \multicolumn{10}{|l|}{ MCT positive } \\
\hline A & 39.7 & & 3.24 & 83.5 & 3.98 & 84.5 & 15.7 & 0.059 & 293 \\
\hline B & 25.0 & & 2.34 & 128.6 & 2.86 & 134.9 & 29.1 & 0.034 & 569 \\
\hline C & 16.4 & & 2.02 & 125.3 & 2.56 & 133.3 & 61.7 & 0.120 & 133 \\
\hline D & 17.2 & & 3.09 & 109.2 & 3.97 & 116.8 & 48.7 & 0.155 & 102 \\
\hline E & 36.4 & & 2.43 & 92.4 & 2.82 & 89.5 & 16.0 & 0.037 & 512 \\
\hline $\mathrm{F}$ & 29.7 & & 3.54 & 101.4 & 4.89 & 115.9 & 29.7 & 0.313 & 49 \\
\hline G & 25.8 & & 4.45 & 100 & 5.82 & 107.6 & 22.5 & 0.039 & 475 \\
\hline Mean $\pm \mathrm{SD}$ or median (IQR) & $25.8(19.1)$ & $14.1 \pm 3.5$ & $3.01 \pm 0.83$ & $105.8 \pm 16.5$ & $3.84 \pm 1.20$ & $111.8 \pm 19.6$ & $29.1(32.7)$ & $0.059(0.118)$ & $293(410)$ \\
\hline \multicolumn{10}{|l|}{ MCT negative } \\
\hline $\mathrm{H}$ & 15.5 & & 1.92 & 85.3 & 2.44 & 90.4 & 46.8 & 0.034 & \\
\hline I & 35.0 & & 4.52 & 113.6 & 5.02 & 103.9 & 20.8 & 0.030 & \\
\hline J & 37.1 & & 2.87 & 101.4 & 3.62 & 105.5 & 16.9 & 0.020 & \\
\hline K & 30.0 & & 3.41 & 104.9 & 4.85 & 130 & 42.9 & 0.075 & \\
\hline L & 30.7 & & 3.69 & 100.5 & 4.64 & 104.5 & 17.6 & 0.020 & \\
\hline M & 35.2 & & 5.78 & 136.3 & 7.23 & 140.4 & 18.3 & 0.030 & \\
\hline N & 14.8 & & 2.56 & 133.3 & 3.08 & 134.5 & 17.9 & 0 & \\
\hline Mean \pm SD or (Median) & $30.7(19.7)$ & $14.1 \pm 3$ & $3.53 \pm 1.29$ & $110.8 \pm 18.5$ & $4.41 \pm 1.57$ & $115.6 \pm 19$ & $18.3(25.3)$ & $0.030(0.014)$ & \\
\hline p-value & 0.45 & ns & 0.22 & 0.24 & 0.31 & 0.45 & 0.29 & 0.03 & \\
\hline
\end{tabular}

ns $=$ non significant.

individuals had a lower PD15 compared to their individual PD15 at day 0 and day 7 (data not shown).

With asthma therapy consisting of budesonide for 14 days and additional montelukast for 7 days, maximum fall in $\mathrm{FEV}_{1}$ after ECT decreased significantly (median drop in FEV1 during exercise 21.7\% (IQR 26.5\%) on day 0, $11.9 \%$ (IQR $13.4 \%$ ) on day 7 and $6.7 \%$ (IQR $8.7 \%$ ) on day 14). Medians were significantly different between these points in time (day 0 vs. day $7 \mathrm{p}=0.006$, day 0 vs. day 14 $\mathrm{p}=0.001$ and day 7 vs. day $14 \mathrm{p}=0.045$ (Figure 1 ).

Airway hyperresponsiveness to mannitol showed a similar pattern; RDR in the MCT decreased between day 0 and day 14 (median RDR in MCT day $0: 0.036 \% / \mathrm{mg}$ (IQR $0.059 \% / \mathrm{mg}$ ), day 7: $0.021 \% / \mathrm{mg}$ (IQR $0.027 \% / \mathrm{mg}$ ) and day 14: $0.013 \% / \mathrm{mg}$ (IQR $0.016 \% / \mathrm{mg}$ ), comparison of means were as follows: change between day 0 and day 7 : $\mathrm{p}=0.064$, between day 0 and day 14: $\mathrm{p}=0.064$ and between $\mathrm{d} 7$ and d14: $\mathrm{p}=0.0167$ (Figure 2).

There was a high correlation between the change in fall of FEV1 during exercise when day 0 was compared with day 14 and the change in RDR in the MCT between day 0 and day $14(\mathrm{r}=0.538, \mathrm{p}=0.047$, Figure 3$)$.

This study shows that half of the asthmatic children and adolescents with exercise-induced bronchoconstriction also have bronchial hyperresponsiveness to mannitol. A structured intervention during hospitalization for pulmonary rehabilitation including a step-up treatment with inhaled corticosteroids and a leukotriene inhibitor decreases airway hyperresponsiveness to exercise and to inhaled mannitol. Evidence exists that exercise itself may positively influence airway hyperresponsiveness [18]. Whether the effect observed was caused by the pharmacological treatment or the structured exercise program cannot be distinguished in our study. Another limitation of our study may be the open-label design, which might have had an involuntary effect on the challenge tests.

Not all of our patients with a loss of FEV1 during exercise of greater than 15\% also had a drop in FEV1 during MCT. Our study supports the findings of Anderson et al. who found a low sensitivity and specificity (59\% and 65\% respectively) of MCT to identify exercise induced bronchoconstriction in 509 children and adults [19]. This is in accordance with a recent study in elite swimmers where Clearie and coworkers could not demonstrate an association between the outcome of MCT and a sport specific exercise test [20].

Exercise and eucapnic voluntary hyperventilation $(\mathrm{EVH})$ are standardized tests to diagnose EIB. Indirect challenge tests including testing with exercise, EVH, mannitol or hypertonic saline cause the release of endogenous mediators that cause the airway smooth muscle to contract and the airways to narrow [21]. Holzer et al. compared the MCT with eucapnic hyperventilation (EHV) in elite summer sport athletes and reported a strong association between the responses to 
Table 2 Comparison of exercise (ECT) and mannitol (MCT) challenge test results in 14 patients with exercise induced bronchoconstriction

\begin{tabular}{llll}
\hline Day 0 (Baseline) & & & \\
\hline & MCT positive & MCT negative & Total \\
\hline ECT positive & 7 & 7 & 14 \\
ECT negative & 0 & 0 & 0 \\
Total & 7 & 7 & 14
\end{tabular}

Efficiency of MCT for the diagnosis of a positive $E C T=50 \%$

\begin{tabular}{llll}
\hline Day 7 (under budesonide therapy) & & \\
& MCT positive & MCT negative & Total \\
ECT positive & 2 & 2 & 4 \\
ECT negative & 5 & 5 & 10 \\
Total & 7 & 7 & 14
\end{tabular}

Efficiency of MCT for the diagnosis of a positive ECT $=50 \%$

Day 14 (under budesonide and montelukast therapy)

$\begin{array}{llll} & \text { MCT positive } & \text { MCT negative } & \text { Total } \\ \text { ECT positive } & 0 & 2 & 2 \\ \text { ECT negative } & 2 & 10 & 12 \\ \text { Total } & 2 & 12 & 14\end{array}$

Efficiency of MCT for the diagnosis of a positive ECT $=71 \%$

these different challenges [22]. In their study 24 out of 25 subjects with a positive EHV challenge also had a positive mannitol challenge. Using the EVH challenge as the gold standard for exercise-induced bronchoconstriction, the mannitol challenge had a sensitivity of $96 \%$ and specificity of $92 \%$ for identifying athletes with a positive $\mathrm{EVH}$. However during EVH individuals must inhale a standardized dry gas in a controlled fashion and ventilation is monitored in order to reach the target ventilation rate and volume. For an exercise test, however, individuals need to exercise on a treadmill or a bicycle while breathing dry air and exercise intensity is monitored and guided by measuring heart rate and not ventilation.

In our study population we could show an effect of antiinflammatory treatment with budesonide and montelukast on airway hyperresponsiveness to exercise and mannitol. Brannan and co-workers have shown that inhaled steroids decrease reactivity in the MCT and Leuppi and co-workers suggested that MCT can be used to predict treatment failure and exacerbation during step-down of asthma therapy $[13,14]$. Investigating short-term effects of montelukast on airway responsiveness to MCT, Anderson did not report a decrease in sensitivity to mannitol but a faster recovery from bronchoconstriction after MCT [23].

While we could show significant impact of treatment on the ECT outcomes, we found only a trend towards decreased reactivity in the MCT. There are several possible explanations for this finding. The intervention period was relatively short and is quite likely that ongoing treatment with budesonide and montelukast could have further decreased the patient's sensitivity in the MCT. The relatively small sample size raises the concern that a type II error has occurred and led to an insignificant result. However, there was a significant correlation between the treatment response of ECT and MCT. Most of the patients

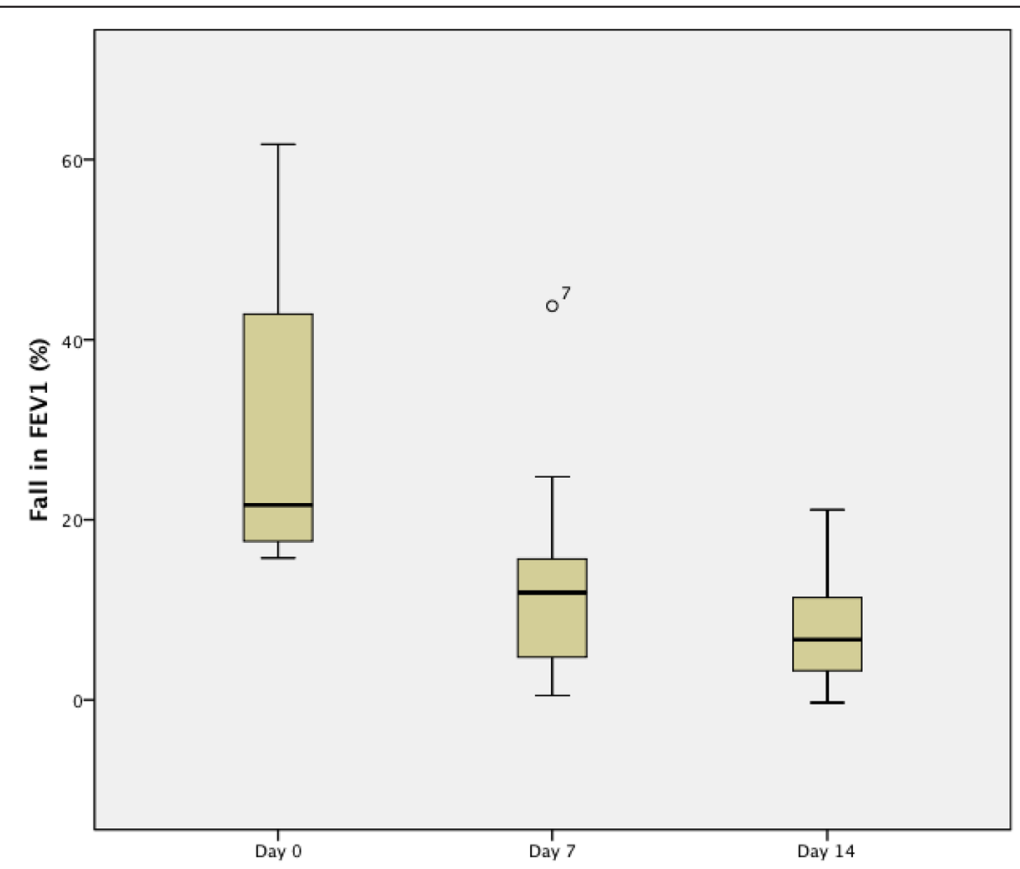

Figure 1 Boxplot of fall in FEV1 during exercise challenge test at day 0, day 7 and day 14 in 14 individuals with exercise induced bronchoconstriction. 


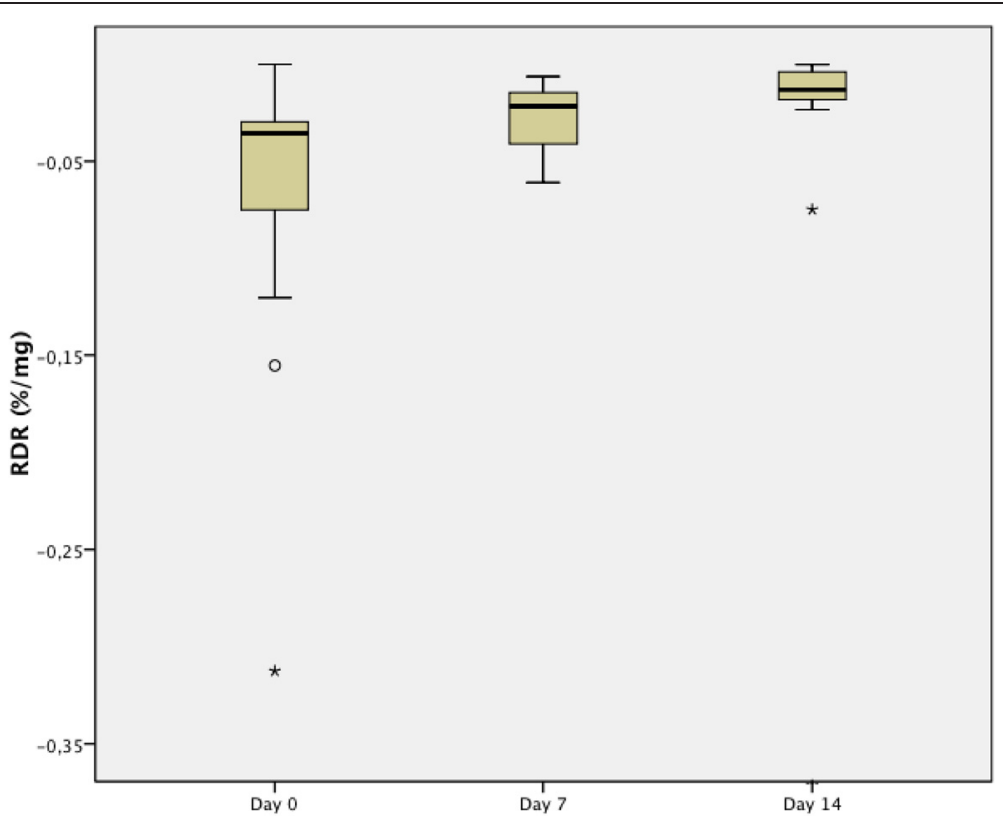

Figure 2 Boxplot of mannitol response dose ratio at day 0 , day 7 and day 14 in 14 individuals with exercise induced bronchoconstriction.

who were included in this study were not living in the area of the Alpine Children's Hospital. Davos is known to be the highest city in Europe located about 1560 meters (5120 feet) above sea level in the Swiss Alps. One can hypothesize that adaptation to the higher altitude as well as the regular exercise as part of the rehabilitation program led to a decrease in ventilation and thus the stimulus during the ECT and therefore a lower sensitivity for the diagnosis of exercise induced bronchoconstriction. However we did not assess ventilation during ECT testing.

Limitations of the study are its observational design, relatively small sample size as well as the absence of a control group that underwent pharmacological treatment without concurrent training. Conclusions which can be drawn from the study must therefore be made in the light of these limitations.

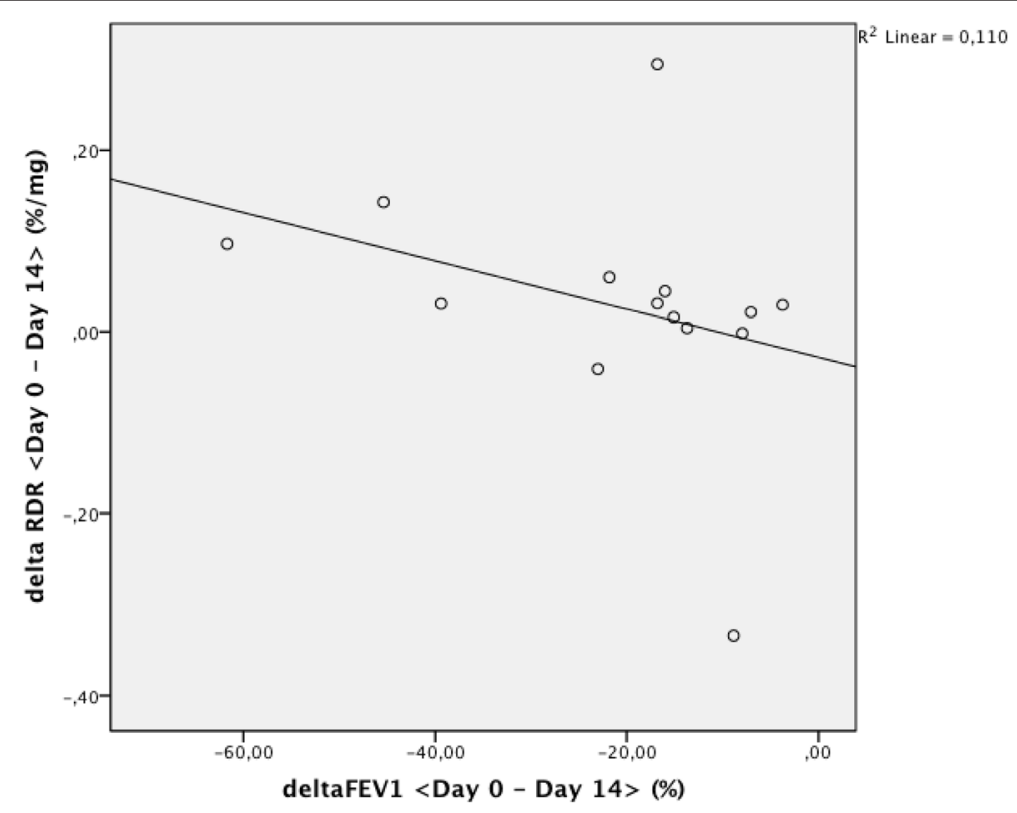

Figure 3 Correlation of treatment response on MCT and ECT reactivity in 14 individuals with exercise induced bronchoconstriction $(r=0.538, p=0.047)$. 


\section{Conclusions}

Children and adolescents with asthma and exercise induced bronchoconstriction repeatedly underwent challenge tests with exercise and mannitol. A multimodal treatment concept including physical training and medical treatment with an inhaled steroid and a leukotriene inhibitor resulted in a decrease in airway hyperresponsiveness to both exercise and mannitol.

\section{Abbreviations}

AHR: Airway hyperresponsiveness; BPT: Bronchial provocation test ECT: Exercise challenge test; ElB: Exercise-induced bronchoconstriction; EVH: Eucapnic voluntary hyperventilation; FEV1: One second forced expiratory volume; FVC: Forced vital capacity; ICS: Inhaled corticosteroids; MCT: Mannitol challenge test; ns: Non significant; IQR: Interquartile range; RDR: Response-dose-ratio; PD $_{15}$ : Provoking dose of mannitol to cause a $15 \%$ fall in $\mathrm{FEV}_{1}$; SD: Standard deviation.

\section{Competing interests}

The study was supported financially by a grant to the corresponding author from Merck Sharp \& Dohme AG, Switzerland, producers of Montelukast. Merck Sharp \& Dohme AG, Switzerland had no role in study design, data collection and analysis, decision to publish, or preparation of the manuscript.

\section{Authors' contributions}

J, BK and TM made substantial contributions to conception and design of the study. TM, SS and AG made substantial contributions to the acquisition of data. SST, TM, DM, AJ, LJ, PC, BK and $J$ to analysis and interpretation of data. SST, AJ and PC were involved in drafting the manuscript and AT in revising it critically for important intellectual content. All authors read and approved the final manuscript.

\section{Acknowledgements}

The use application for mannitol described in this study is covered by United States Patient no. 5817028 and internationally by PCT/AU95/000086. The patent is owned by Central Sydney Area Health Service, NSW, Australia and is licensed to Pharmaxis Ltd, French Forrest, NSW, Australia.

\section{Author details}

${ }^{1}$ Internal Medicine, University Hospital Basel and University of Basel, Basel, Switzerland. ${ }^{2}$ University Childrens Hospital Basel, Basel, Switzerland. ${ }^{3}$ Alpine Childrens Hospital Davos, Davos, Switzerland. ${ }^{4}$ Clinical Pharmacology and Toxicology, University Hospital Basel, Basel, Switzerland. ${ }^{5}$ Internal Medicine, Kantonal Hospital Baselland and University of Basel, Basel, Switzerland. ${ }^{6}$ University Clinic of Internal Medicine, Kantonsspital Baselland, Liestal, Switzerland.

Received: 5 May 2014 Accepted: 9 July 2014

Published: 2 August 2014

\section{References}

1. Sterk PJ, Fabbri LM, Quanjer PH, Cockcroft DW, O'Byrne PM, Anderson SD, Juniper EF, Malo JL: Airway responsiveness: standardized challenge testing with pharmacological, physical and sensitizing stimuli in adults: report working party standardization of lung function tests, European community for steel and coal: official statement of the European respiratory society. Eur Respir J Supp/ 1993, 16:53-83.

2. Leuppi JD, Brannan JD, Anderson SD: Bronchial provocation tests: the rationale for using inhaled mannitol as a test for airway hyperresponsiveness. Swiss Med Wkly 2002, 132(13-14):151-158.

3. Anderson SD: Provocative challenges to help diagnose and monitor asthma: exercise, methacholine, adenosine, and mannitol. Curr Opin Pulm Med 2008, 14(1):39-45.

4. Leuppi JD: Bronchoprovocation tests in asthma: direct versus indirect challenges. Curr Opin Pulm Med 2014, 20(1):31-36.

5. Haby MM, Anderson SD, Peat JK, Mellis CM, Toelle BG, Woolcock AJ: An exercise challenge protocol for epidemiological studies of asthma in children: comparison with histamine challenge. Eur Respir J 1994, 7(1):43-49.
6. Haby MM, Peat JK, Mellis CM, Anderson SD, Woolcock AJ: An exercise challenge for epidemiological studies of childhood asthma: validity and repeatability. Eur Respir J 1995, 8:729-736.

7. Anderson SD: Issues in exercise-induced asthma. J Allergy Clin Immunol 1985, 76(6):763-772.

8. Gotshall RW: Exercise-induced bronchoconstriction. Drugs 2002, 62(12):1725-1739.

9. Anderson SD, Brannan J, Spring J, Spalding N, Rodwell LT, Chan K, Gonda Walsh A, Clark AR: A new method for bronchial-provocation testing in asthmatic subjects using a dry powder of mannitol. Am J Respir Crit Care Med 1997, 156:758-765.

10. Brannan JD, Anderson SD, Perry CP, Freed-Martens R, Lassig AR, Charlton B: The safety and efficacy of inhaled dry powder mannitol as a bronchial provocation test for airway hyperresponsiveness: a phase 3 comparison study with hypertonic (4.5\%) saline. Respir Res 2005, 6:144

11. Brannan JD, Koskela H, Anderson SD, Chew N: Responsiveness to Mannitol in asthmatic subjects with exercise- and hyperventilation-induced asthma. Am J Respir Crit Care Med 1998, 158:1120-1126.

12. Subbarao P, Brannan JD, Ho B, Anderson SD, Chan HK, Coates AL: Inhaled mannitol identifies methacholine-responsive children with active asthma. Pediatr Pulmonol 2000, 29:291-298.

13. Brannan JD, Koskela H, Anderson SD, Chan HK: Budesonide reduces sensitivity and reactivity to inhaled mannitol in asthmatic subjects. Respirology 2002, 7:37-44.

14. Leuppi JD, Leuppi JD, Salome CM, Jenkins CR, Anderson SD, Xuan W, Marks GB, Koskela H, Brannan JD, Freed R, Andersson M, Chan HK, Woolcock AJ: Predictive markers of asthma exacerbation during stepwise dose-reduction of inhaled corticosteroids. Am J Respir Crit Care Med 2001, 163:406-412.

15. American Thoracic Society: Standardization of spirometry, 1994 update. Am J Respir Crit Care Med 1995, 152(3):1107-1136.

16. Weng TR, Levison H: Standards of pulmonary function in children. Am Rev Respir Dis 1969, 99(6):879-894.

17. Crapo RO, Casaburi R, Coates AL, Enright PL, Hankinson JL, Irvin CG, Maclntyre NR, McKay RT, Wagner JS, Anderson SD, Wockcroft DW, Fish JE, Sterk PJ: Guidelines for methacholine and exercise challenge testing-1999: this official statement of the American thoracic society was adopted by the ATS board of directors, July 1999. Am J Respir Crit Care Med 2000, 161:309-329.

18. Scichilone N, Morici G, Zangla D, Arrigo R, Cardillo I, Bellia V, Bonsignore MR: Effects of exercise training on airway closure in asthmatics. J Appl Physiol (1985) 2012, 113(5):714-718.

19. Anderson SD, Charlton B, Weiler JM, Nichols S, Spector SL, Pearlman DS: Comparison of mannitol and methacholine to predict exercise-induced bronchoconstriction and a clinical diagnosis of asthma. Respir Res 2009, 10:4.

20. Clearie KL, Williamson PA, Vaidyanathan S, Short P, Goudie A, Burns P, Hopkinson P, Meldrum K, Howaniec L, Lipworth BJ: Disconnect between standardized field-based testing and mannitol challenge in Scottish elite swimmers. Clin Exp Allergy 2010, 40(5):731-737.

21. Anderson SD: Indirect challenge tests: airway hyperresponsiveness in asthma: its measurement and clinical significance. Chest 2010, 138(2 Suppl):25S-30S.

22. Holzer K, Anderson SD, Chan HK, Douglass J: Mannitol as a challenge test to identify exercise-induced bronchoconstriction in elite athletes. Am J Respir Crit Care Med 2003, 167(4):534-537.

23. Brannan JD, Anderson SD, Gomes K, King GG, Chan HK, Seale JP: Fexofenadine decreases sensitivity to and montelukast improves recovery from inhaled mannitol. Am J Respir Crit Care Med 2001, 163:1420-1425.

doi:10.1186/1471-2431-14-196

Cite this article as: Török et al.: An open-label study examining the effect of pharmacological treatment on mannitol- and exercise-induced airway hyperresponsiveness in asthmatic children and adolescents with exercise-induced bronchoconstriction. BMC Pediatrics 2014 14:196. 